\title{
AVANCES EN EL MARCO JURÍDICO Y ADMINISTRATIVO DE LAS INSTITUCIONES DE SEGURIDAD PÚBLICA
}

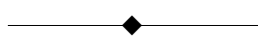

\section{RESUMEN}

Las modificaciones realizadas en 1994 al marco jurídico y administrativo de las instituciones de seguridad pública permitieron implementar el modelo de relación intergubernamental de autoridad superpuesta, asegurando el funcionamiento de vínculos verticales y horizontales de cooperación entre los distintos ámbitos de gobierno. Situación que permitió coadyuvar las operaciones de los organismos de la seguridad pública para atender la problemática de la seguridad.

Palabras clave: seguridad pública, instituciones, marco jurídico, legislación, colaboración interinstitucional.

\section{ABSTRACT}

The modifications made in 1994, to the legal and administrative frame of the institutions of public security allowed to implement the model of intergovernmental relation of superposed authority, supporting the operation vertical and horizontal bonds of cooperation between the different scopes of government. Situation that allowed to help the operations of the organisms of the public security to take care of the security problems.

Keywords: public security, institutions, legal frame, legislation, interinstitutional collaboration.

\footnotetext{
* Subdirectora de información y estadística, Secretaría de Seguridad Pública del Estado de Baja California. Estudiante del doctorado en Ciencias SOCIALES APLiCAdas, el Colef. BECARIA PROMEP. Correo electrónico: jalavez@c4bc.gob.mx
} 


\section{INTRODUCCIÓN}

La seguridad pública es una de las preocupaciones centrales no sólo en México, sino en la mayor parte del mundo, derivada del incremento delas tasas deincidencia delictiva, el crecimiento en el porcentaje de delitos violentos, la baja eficacia de los sistemas de prevención y sanción del delito, entreotras (Carranza, 1997; Mascott, 2003). Tal situación ha propiciado en la ciudadanía una creciente percepción deinseguridad.

En México, como en Baja Cal ifornia, los ciudadanos y las organizaciones se preguntan quéha hecho el Estado, y en particular las instituciones responsables de la seguridad pública, para contener la ola de del incuencia.

Está claro que la seguridad pública es responsabilidad directa del Estado; sin embargo, en los últimos diez años la sensación de descuido de las autoridades o de inseguridad pública se ha incrementado, sobretodo antela crecienteola decrímenes, la impunidad y la corrupción (Vértiz, 2001:308-309; Del Castillo, 2001: 275-309). Ello ha forzado a las autoridades a retomar el tema, obligándolas a elaborar políticas queproporcionen protección. El Plan Nacional de Desarrollo 1995-2000 incluyó estrategias de anticorrupción y ética, un programa de modernización administrativa y se elaboraron las Leyes de Responsabilidad delos Servidores Públicosy deA dquisiciones y Obra Pública. Adicionalmente, en enero de 2001 se llevó a cabo la instalación de la comisión intersecretarial para la transparencia y el combatea la corrupción.

En estesentido, el presentedocumento describelas accionesque en materia deseguridad seiniciaron a partir de 1994, una vez identificado que la legislación y conformación estructural bajo la cual sehabíainstrumentado la operatividad dela seguridad pública no permitía organizar acciones quellevaran a detener el problema de la delincuencia a nivel regional o municipal.

En estetrabajo se describen las diversas formas en queseaborda el fenómeno dela delincuencia, el concepto deseguridad pública y el papel delas instituciones, los antecedentes jurídicos administrativos, las modificaciones al marco y la reconformación delas insti- 
tuciones. Asimismo, se puntualiza la forma en quevieneoperando la legislación en el estado de Baja California.

\section{EL FENÓMENO MUNDIAL DE LA DELINCUENCIA}

En todo el mundo el fenómeno de la violencia ha sido uno de los grandes temas de estudio; no hay excepción, lo vemos en países desarrolladosy en vías de desarrollo. Seestima quela violencia en las ciudades ha aumentado en tres y hasta cinco por ciento en los dos últimos decenios (Unicri, 1995). ${ }^{1}$ Las formas deviolenciay pautas delictivas urbanas varían de acuerdo con las distintas regiones, países o ciudades (Unicri, 1995), por lo que no es posible hacer generalizaciones; sin embargo, existe un grupo de delitos que se encuentran presentes con regularidad en todas las ciudades.

De acuerdo con el Instituto Interregional de las Naciones Unidas para Investigaciones sobrela Delincuencia y la Justicia (Unicri), la mayor partede los delitos cometidos en las ciudades son dedos tipos: el primero catal ogado como delitos contra la propiedad (robos, particularmente de autos), los cuales constituyen más de la mitad delos delitos cometidos en lasciudades detodo el mundo. El segundo tipo son los crímenes violentos (homicidios, violaciones y secuestros), éstos representan, en promedio, entre $25 \%$ y $30 \%$ del total de los delitos delas ciudades.

Bajo diferentes enfoques, seha buscado explicar las causas dela delincuencia, por lo queencontraremos desdeteorías quesebasan en el comportamiento del individuo² (Cooper, 2000), o bien en las

\footnotetext{
${ }^{1}$ Según datos del Instituto Interregional de las Naciones Unidas para Investigaciones sobre la Delincuencia y la Justicia (Unicri) y del Estudio Internacional sobre Víctimas del Delito (1988-1994) del Ministerio de Justicia de los Países Bajos, con base en un muestreo de 74000 personas de 39 países.

2 Teorías que enfocan distintos aspectos de la conducta humana como las Motivaciones y las Metas de Éxito (R. Merton), el A prendizaje de la Conducta Delictual (E. Sutherland), Problemas de la Familia de Origen, Estrato Socioeconómico, Droga, Alcohol y Familia (G. y S. Gluecks), Intervalos Etarios y Estado Civil (G. Sykes), Autopercepción y Rotulación (Becker y E. Lemert), Prejuicio Interétnico y Marginalidad (P. Heintz), Explicaciones del Actor (A. Schutz).
} 
circunstancias que le rodean, en una combinación de ambas, ${ }^{3}$ hasta las teorías que estudian la influencia de la infraestructura urbana en el comportamiento social (Harvey, 1976; Garrido, et al ., 1999). ${ }^{4}$

Las particularidades para quelos delitos se presenten en ciudades en todas partes del mundo son: a) tasa dedesempleo elevado; b) deficiente mantenimiento de las infraestructuras urbanas; c) mediocridad delas infraestructuras, traduciéndose en problemas de agua, dehigieney detransporte, situación que impacta principalmente a los pobres de las zonas urbanas; d) problemas medioambientales, en particular la contaminación atmosférica, del agua y el ruido, e) el clima político y económico, f) la pérdida delas tradiciones y los val ores locales, y g) el grado de cohesión social y de solidaridad entre las comunidades urbanas. Este último tiene una graveconsecuencia: la erosión delos val ores moralesy el desmoronamiento de las estructuras e instituciones sociales, como la familia o el vecindario, ocasionando que las comunidades sean más vulnerables a la violencia y a la delincuencia urbana.

Las teorías del control y desviación social son de las más influyentes dentro deesta vertiente. Deella se desprende que las acciones de delincuencia se verifican cuando el vínculo del individuo con la sociedad serompeo sevuelvefrágil. La sociedad debe realizar una función de contención social a través de la presión desus instituciones y mediante una social ización adecuada lograr que los individuos a su vez interioricen una autocontención social. La teoría del desvío social sitúa en particular el origen de la violencia y la delincuencia en el desvío de ciertos individuos del sistema de val ores culturales imperanteen una determinada sociedad.

\footnotetext{
${ }^{3}$ Desde un ángulo psicosocial: Teoría del Modernismo Psicosocial (A. Inkeles; J. Kahl; D. Lerner), la A nomia Individual (L. Srole), el Paradigma del Interaccionismo Simbólico, la Teoría de la Rotulación (H. Becker; E. Lemert) y el Naturalismo de D. Matza.

${ }^{4}$ Escuela de Ecología Humana de Chicago entre los que encontramos a Park y Burgess.
} 
En este sentido se observa un debilitamiento del orden social, aunque también político, derivado de los cambios producidos en las causas de la violencia en las últimas décadas como la globalización, la pérdida de peso del Estado, la caída de la sociedad industrial y la crisis de la modernidad.

Respecto a la situación actual del Estado, existe un gran consenso en torno a la idea de quecada vez es menos capaz decumplir sus funciones básicas y que en la práctica la definición weberiana pareceya no responder a las características del Estado contemporáneo.

Particularmente en materia de seguridad pública, existela sensación en la población de quelos crímenes quedan impunes, lo que revela una aguda crisis en las formas de acción de los sistemas judiciales. En razón deesto, el Estado-nación aparececada vez más como incapaz de velar por la seguridad de los ciudadanos y de proteger sus bienes, tanto materiales como simbólicos, en tanto que la fragmentación cultural contribuye a tornar más débiles las formas deacción del Estado, ya queéste no puede reclamar para sí el monopolio dela identidad cultural desus ciudadanos.

\section{SEguRIDAD PÚBLICA}

Se discutehoy, más que nunca, acerca del significado dela seguridad, sobre las políticas que pueden hacer un mundo con sociedades más seguras, y sobre los factores que causan inquietud, temor e inseguridad a la gente y a los Estados. La inseguridad ciudadana es una mezcla de inseguridades, las propias (complejos, miedos, ansiedades), las externas (empleo precario o nulo, la impotencia antelas injusticias o el no impacto del individuo en la sociedad, la presión consumidora, el dinero como valor único, etcétera) y las victimizadoras (ser víctimas concretas de robos, amenazas, abusos, violaciones, entre otros) (Salinas, 2004).

En el imaginario colectivo creemos que existe una familia, un trabajo, un entorno, ideales. Los esfuerzos de la mayoría de los individuos seinvierten en al canzar estos ideales o por el contrario, huir deellos deforma agresiva. La tensión entrelo deseado y lo real 
genera violencia. Merton destaca como “hipótesis central [...] que la conducta anómala puede considerase desde el punto de vista sociológico como síntoma de disociación entre las aspiraciones culturalmente prescritas y los caminos social mente estructurales para llegar a dichas aspiraciones". A medida quenuestra sociedad seconvierteen fabricantedesueños, la frustración no hacemásque aumentar la sensación de inseguridad.

Entonces, ¿québusca protegerse a través dela seguridad pública?, ¿qué significa garantizar la tranquilidad pública y la seguridad del orden público y de sus instituciones, cuyo mantenimiento se encuentra a cargo de organismos del Estado especial izados en ello, básicamente policías y tribunales? Por tanto, implica la seguridad interior del Estado (Cornet, 2002).

La seguridad pública es considerada como un bien público y debeser provista por el Estado, tanto para cumplir con su función esencial de proteger los bienes y la integridad física de las personas, como para que se alcance un nivel de seguridad socialmente eficientequepromueva el desarrollo del país.

En sentido propio, la seguridad pública, lo mismo que la paz pública y el orden público, son bienes generados por el conjunto de condiciones objetivas impulsadas por el Estado y creadas por el grupo social mismo, con la final idad de obtener y alcanzar beneficios.

Sin embargo, mayor seguridad pública no es sinónimo demayores medidas represivas y/ o antidelincuenciales; tampoco es proporcional ni se combate sólo con el despliegue de más o menos fuerza policial en las calles.

\section{EL PAPEL DE LAS INSTITUCIONES}

En México la eficacia delos cuerpos policiacos, ministerios públicos y tribunales para sancionar el delito ha sido muy limitada, en especial a partir dela década delos años noventa, luego del incremento en las tasas nacionales de delincuencia. En el fondo, la inseguridad radica en la impunidad de quienes, debiendo cumplir y hacer cumplir la ley, protegen y alientan la delincuencia. 
Figura 1. Ciclo dela desconfianza antela impunidad.

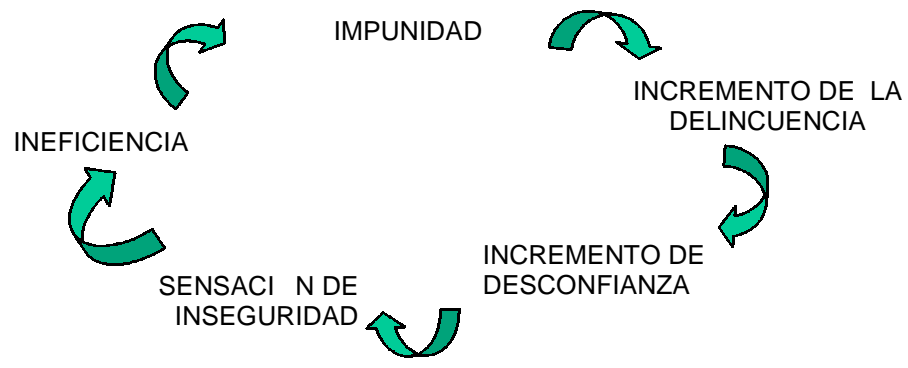

FUENTE: Elaboración propia.

En materia deseguridad pública las prácticas político-administrativas, decoordinación entrelos cuadros medios y al gunas élites depoder, sufren una fuertedescomposición (Aguilar, 1996). Esto se debe principal mentea la falta deun sistema deadministración de justicia eficiente e imparcial; a la débil coordinación entre las de pendencias involucradas; a la deficiente actuación del Ministerio Público en la integración delas averiguaciones previas; al incumplimiento de las sentencias de los tribunales; a obstáculos para el acceso a la justicia, especial menteen los estados; y a la fal ta de una investigación efectiva delas denuncias de corrupción judicial.

Tal situación sugiere un desorden en el marco de la colaboración intergubernamental.

\section{BASES Y ESTRUCTURAS COM PONENTES DE LAS RELACIONES INTERGUBERNAMENTALES (RIGS)}

Las estructuras gubernamental es son importantes para la configuración de las pautas de interacción social, asimismo funcionan como indicadores desu conducta y dela política pública según lo señal ado por March y Olsen (Agranoff, 1997:136), por lo queidentificarlasy observar su comportamiento en el tiempo permiteconocer si prevalecela autoridad coordinada, planteada bajo un esquema derelaciones autónomas deautoridad nacional y estatal, en donde las dos jurisdicciones tienen esferas separadas de poder y control, 
que corresponde al primer modelo de Wright; o de autoridad inclusiva, donde predomina la jerarquía dentro de la relación de autonomía de las instituciones gubernamentales, considerándose a los gobiernos locales y estatales como simples apéndices de un poderoso gobierno nacional, que domina un sistema centralizado (segundo modelo); o dentro del tercer modelo, deautoridad superpuesta 0 traslapante, en el que se presentan las relaciones intergubernamentales como una conducta pautada, de manera interdependientey negociada, entrefuncionarios nacionales, estatales y locales; donde el contacto e intercambio entre éstos puede ser simultáneamente cooperativo y competitivo.

Figura 2. Model os de autoridad en las relaciones intergubernamentales.
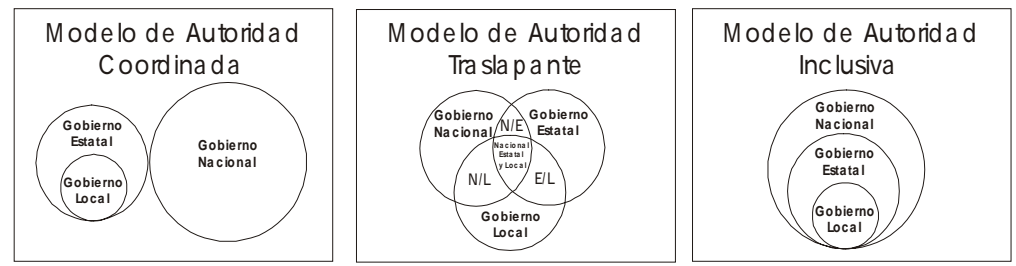

Fuente: Tomado de Deil Wright (1997).

ANTECEDENTE JURÍDICO-ADMINISTRATIVO

DE LA SEGURIDAD PÚBLICA

En el caso de la seguridad pública podemos encontrar un antes y un después de 1994 en cuanto a sus estructuras y marco jurídico. Estas modificaciones son resultado de la inoperabilidad de sus instituciones, a las cuales seles acusa de queen lugar deatender el problema de la delincuencia, propiciaban situaciones de desconfianza, corrupción y descuido dela profesionalización desuscuerpos policiacos.

En estesentido, y antes de 1994, se pueden observar estructuras o instituciones encargadas de la procuración, administración de justicia y preventivas, queoperaban cada una en su ámbito decompetencia; podría señal arse quela forma deoperación estaba bajo el 
model o de autoridad coordinada. El marco jurídico que regía las políticas y estrategias de seguridad pública no había ayudado a desarrollar un trabajo coordinado o de conjunto, no permitía impulsar mecanismos de coordinación, determinar lineamientos de acción entrelas diversas instituciones de seguridad pública; cada instancia, en su ámbito, manejaba sus propios objetivos y metas bajo una visión parcial.

En principio tenemos el marco de relación y operación de los gobiernos e instituciones bajo el federalismo, que por sus propias características no pueden ser descentralizadas, pero sí operadas en todos los ámbitos para salvaguardar la seguridad y los bienes dela población. En el caso del sistema federal mexicano, la Constitución Política observa tres tipos decircunscripciones gubernamentales: la federal, la estatal y la municipal. Esta composición establece la estructuración delos órdenes de gobierno, la composición jurisdiccional territorial delas atribuciones decompetencia y autoridad para cada uno de éstos.

Por medio delaconformación del pacto federal, los estadosmiembros seden atribuciones a una instancia de gobierno superior, sin perder con ello su autonomía y autodeterminación. Es decir, bajo el principio fundamental deéste, la expectativa es la unión deesfuerzos conjuntos para la búsqueda del desarrollo y bienestar común (párrafos 1o. y 20. del artículo 25 Constitucional), queno significa sometimi ento delas partes por un entesuperior, sino la conformación deacuerdos entrelos órdenes degobierno.

En el ámbito federal, la Procuraduría General de la República (PGR), por medio desus representaciones locales, es responsable de la recopilación deevidencias einvestigación, los Ministerios Públicos Federales (MPF) integran las averiguaciones previas, además del material probatorio, para quelosJuzgados deCircuito evalúen y dictaminen la situación jurídica de los detenidos.

En el ámbito estatal , I a Procuraduría General de Justicia del Estado (PGJE), mediante los Ministerios Públicos del fuero común (MPC), distribuidos en agencias receptoras y especializadas, seresponsabiliza de desarrollar investigaciones, integrar averiguaciones, cumplir con las órdenes deaprehensión y reaprehensión, para 
que los Juzgados locales dictaminen la situación jurídica correspondiente.

La prevención delos delitos era exclusividad delos cuerpos de seguridad municipales. Su carácter preventivo sólo consistía en participar en la vigilancia urbana, auxilio y asistencia ciudadana, atención de las denuncias, detención en flagrancia de presuntos sospechosos de al gún delito y trasladarlos ante los ministerios del fuero federal o común.

Los ay untami entos estaban facultados para establecer los Bandos dePolicía y Buen Gobierno en sus respectivos municipios, con facultades administrativas exclusivas para la imposición de sanciones por faltas cometi das a los regl amentos de los Bandos, careciendo de facultades o atribuciones para la imposición de penas, papel exclusivo de los órganos jurisdiccionales federal o estatal, por medio de los Ministerios Públicos correspondientes. (Párrafo 1o. del artículo 21 Constitucional).

Las corporaciones como la Policía Federal de Caminos y Puertos, Ia Policía Fiscal Federal, o incluso el Ejército M exicano, operaban únicamente para coadyuvar dentro de sus atribuciones jurídicas, y en caso dealgún aseguramiento, sólo trasladaban a los detenidos hacia las instancias correspondientes.

\section{LAS MODIFICACIONES AL MARCO DE LAS RELACIONES}

El cambio inició en 1994 al recrudecerse el problema de inseguridad, aunado a un sinnúmero de problemas económicos del país, obligando al Estado a buscar las medidas necesarias para cumplir con las demandas ciudadanas de seguridad pública. Es entonces que se promueven una serie de modificaciones y se establece la necesidad de mantener una relación coordinada entre instancias deseguridad pública; al final de 1994 se reforma el artículo 21 dela Constitución, así como la ley reglamentaria de coordinación del Sistema Nacional deSeguridad en diciembre de 1995 y seestablece un Sistema Nacional de Seguridad Pública (SNSP).

Previo a la creación del Sistema N acional deSeguridad Pública, se constituyó como órgano superior de coordinación el Consejo 
Nacional de Seguridad Pública del SNSP, quedando establecida la figura deSecretario Ejecutivo. Dicho consejo lo integra el Secretario de Gobernación, el Secretario dela Defensa N acional, el Secretario deMarina, el Secretario de Comunicacionesy Transportes, el Procurador General dela República, los gobernadores delos estados, el Jefe deGobierno del Distrito Federal y un secretario técnico. Las funciones de éste consisten en elaborar las propuestas de contenido del Programa Nacional deSeguridad Pública y someterlas a la aprobación del Consejo; coordinar el servicio nacional deapoyo a la carrera policial y las instituciones nacionales de formación de las policías; administrar y sistematizar los instrumentos de información del Sistema Nacional, así como recabar todos los datos que se requieran; formular sugerencias a las autoridades competentes para que las instituciones de seguridad pública de la Federación, los estados, el Distrito Federal y los municipios, desarrollen de manera más eficaz sus funciones; promover, por conducto de las instituciones deseguridad pública, la realización de acciones conjuntas, conforme a las bases y reglas que emita el Consejo y sin menoscabo de otras que real icen las autoridades competentes; tomar las medidas necesarias para hacer efectiva la coordinación y preservación de la seguridad pública; realizar estudios especializados sobrelas materias de seguridad pública; y además coordinar acciones entrelas policías federales preventivas.

Asimismo, podemos observar queen el Plan Nacional de Desarrollo 1995-2000, ya se reconoce que las políticas y estrategias de seguridad pública no habían sido las más adecuadas para impulsar los mecanismos de coordinación ni para determinar los lineamientos de acción entre las diversas instituciones de seguridad pública. Para lo cual se conforma el Programa Nacional de Seguridad Pública 1995-2000, estableciéndose como el principal elemento decoordinación programática para quelos tres órdenes de gobierno unieran esfuerzos con la finalidad de abatir las incidencias delictivas, proporcionar mayor seguridad a las personas, sus bienes y sus derechos, dando respuesta a una delas demandas más sentidas de la población. 


\section{RECONFORMACIÓN DE LAS INSTITUCIONES}

Bajo el esquema deoperación coordinada se establecen instancias entre los distintos órdenes de gobierno en materia de seguridad pública, tales como el Consejo Nacional deSeguridad Pública, los Consejos Locales de Coordinación, Ios Consejos de Coordinación Delegacionales o Municipales, y los Consejos deCoordinación Regionales. El objetivo de éstos es permitir que a niveles locales o regionales se puedan instrumentar acciones queluego se subirán al seno del Consejo Nacional, sin queesto demeritela operación de una u otra instancia.

FiguRA 3. Instancias superiores de coordinación.
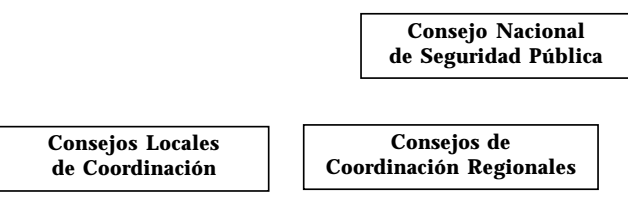

Fuente: Elaboración propia.

A simismo, con objeto de que se instrumenten acciones no sólo regionales, sino específicas, se establecen los espacios por medio delos cuales sellevará a cabo la coordinación en diversas áreas: la Conferencia de Prevención y Readaptación Social, Ia Conferencia deProcuración de Justicia, Ia Conferencia deParticipación Municipal, y las Comisiones Especializadas necesarias.

Figura 4. Espacios de coordinación.

Conferencia de
Procuración de Justicia

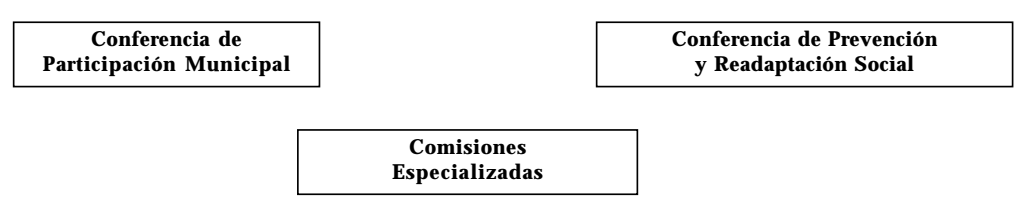

FUENTE: Elaboración propia. 
Se determina a las autoridades para llevar a cabo las funciones deseguridad pública: Ia Policía Preventiva o Policía Municipal , el Ministerio Público y los Tribunales Penales. Éstas últimas se dividen en fuero común y federal. En el primero encontramos losJuzgados de Primera Instancia del Ramo Penal, Ios Tribunales Unitarios y el Tribunal Superior de Justicia o Supremo Tribunal de Justicia. En el fuero federal están los Juzgados de Distrito, los Tribunales Unitarios deDistrito y los Tribunales Colegiados de Circuito.

Las autoridades responsables de la prisión preventiva, ejecución de penas y tratamiento de menores infractores son los directores, alcaldes, guardias y custodios, tanto de los centros de readaptación social, como delos destinados a menores infractores. Y los encargados de proteger las instal aciones y servicios estratégicos del país serán todas las demás autoridades queen razón desus atribuciones deban contribuir directa o indirectamente en materia deseguridad pública.

La misma Ley General que establecelas Bases de Coordinación del Sistema Nacional de Seguridad Pública, incorpora dos instrumentos de coordinación para la integración del SNSP. El primero, comprendido por el Servicio Nacional deA poyo a la Carrera Policial, elemento básico en la formación de los integrantes delas instituciones policiales y en el logro de su dignificación. El segundo instrumento, es el Subsistema del nformación Nacional sobreSeguridad Pública, el cual se integra con la captura, suministro, intercambio y sistematización de información. Dicho subsistema lo componen diversos registros, como el Registro N acional del Personal de Seguridad Pública, el Registro Nacional de Armamento y Equipo, la Estadística de Seguridad Pública y la Información de A poyo a la Procuración de Justicia.

El Sistema Nacional de Seguridad Pública (SNSP) setransformó en el instrumento del Estado mexicano, medianteel cual el problema dela seguridad pública podía ser anal izado bajo una perspectivaglobal.

Dentro del marco del SNSP y reconociendo la obligación del Estado de proporcionar un entorno librea la amenaza dela del incuencia, ya que no puede sólo limitarse al acto coercitivo dela sanción 
del delito, secrea la Policía Federal Preventiva, integrándoseel 30 de noviembre de 2000. Esta tendrá autonomía técnica y operativa en el ejercicio de sus funciones. Asimismo, tendrá por ámbito de competencia el territorio nacional, exclusivamenteen lo queserefiere a la materia federal, todas las zonas federales y fronterizas, parques nacionales, instalaciones hidráulicas, inmuebles, instalaciones y servicios dependientes de la Federación. Sin embargo, la responsabilidad de la institución estará fijada para evitar, dentro delas áreas einstalaciones federales, la comisión dedelitos federales; pero si se cometieren y practicase alguna detención en flagrancia, su deber será entregar a los presuntos responsables al Ministerio Público dela Federación.

Asimismo, para fortalecer la función preventiva, se integra al Sistema Nacional de Seguridad Pública a diversas dependencias dela A dministración Pública Federal, como las Poli cías de Migración, Federal deCaminos y Fiscal Federal, mismas quecambian su organización, estructura y dependencia.

Con ello encontramos que el gobierno federal reduce a tres el número de corporaciones policiacas con las que cuenta: Ia Policía Judicial Federal, dependientedela PGR; Ia Policía Federal Preventiva, dependientedela Secretaría deGobernación y posteriormente al SNSP y la Policía Fronteriza (Grupo Beta), dependiente del Instituto Nacional deMigración (Inami) con funciones preventivasy de vigilancia de las franjas fronterizas.

\section{EL IMPACTO DE LAS MODIFICACIONES \\ EN EL MARCO ESTATAL Y MUNICIPAL}

Una vez estructuradas las acciones einstancias federales, seobserva que los gobiernos estatales adquieren, con baseen diversos artículos constitucionales, facultades jurisdiccionales a través de la regla de exclusión plasmada en el art. 124, con el establecimiento dela división de poderes en los estados en el art. 116, y el reconocimiento a su régimen interno por medio del art. 41. El Poder Legislativo de cada estado tiene la facultad de conformar la legislación local queestructurará el marco jurídico-normativo deoperación de 
las instituciones locales, así como de su relación con la población dentro de su jurisdicción territorial, sin contravenir lo expuesto dentro del pacto federal y las legislaciones que deella emanen.

La competencia jurisdiccional de los gobiernos estatales está delimitada por lo no expresado dentro de la fracc. 1-A del art. 104 Constitucional, que establecela competenciajurisdiccional federal a razón de: “Todas las controversias del orden civil o criminal que sesusciten sobreel cumplimiento y aplicación deleyesfederaleso tratados internacionales celebrados por el Estado Mexicano."

En lo que respecta al municipio, el inciso $h$ ) de la fracc. III del mismo artículo, estipula la seguridad pública, la policía preventiva municipal y tránsito, como funciones y servicios públicos de los cuales es responsable; en concordancia con el art. 21 Constitucional quela define como una función compartida con la federación y el estado, pero acotada dentro de las competencias respectivas de cada uno. Asimismo, se definela observancia delas leyes federales y estatales por partedel municipio, sin perjuicio desu competencia constitucional. Resulta relevantesi consideramos que dentro delas facultades del municipio, la fracc. II del art. 115 Constitucional estableceel “...aprobar deacuerdo con las leyes en materia municipal, los bandos de policía y gobierno, los reglamentos y circulares y disposiciones administrativas de observancia general dentro de sus respectivas jurisdicciones, que organicela admi nistración pública municipal, regule las materias, procedimientos, funciones y servicios públicos de su competencia y aseguren la participación ciudadana y vecinal". A simismo, la fracc. VI del art. 115Constitucional establece que la policía preventiva municipal acatará las órdenes que el Gobernador del Estado le transmita, en aquellos casos en que éstejuzgue como de fuerza mayor o al teración grave del orden público; asimismo, el Ejecutivo Federal tendrá el mando dela fuerza pública en los lugares donde resida, habitual o transitoriamente.

A la administración municipal sele otorga la facultad, en sentido general, de conformar su propia corporación policiaca, la cual estará a cargo del Presidente Municipal en los términos del reglamento correspondiente. 
Para el caso particular de los municipios de Baja California, el artículo 135 dela Ley Orgánica dela A dministración Pública Municipal del Estado establece que los Bandos de Policía y Buen Gobierno expedidos por los ayuntamientos deberán contener “...aquellas disposiciones relativas a los valores protegidos en la esfera del orden público, en lo queserefierea la seguridad general, ...la propiedad y el bienestar colectivo, y el ámbito que protegela integridad delas personas en su seguridad, tranquilidad y disfrute depropiedades particulares, así como la integridad moral del individuo y la familia".

El art. 138estipula que los reglamentos municipales deberán observar sanciones y el art. 143 establece que las normas que contengan los Bandos, Reglamentos y otras disposiciones municipales, deberán ser generalesy obligatoriasen el ámbito municipal, y su aplicación einterpretación correspondea las autoridades municipales.

En estesentido, la Policía de Seguridad Pública Municipal será responsabledel servicio deseguridad pública y tránsito, procurando proporcionar las condiciones necesarias para salvaguardar la integridad física, moral y patrimonial delos habitantes del municipio a fin de que puedan ejercer los derechos que la Constitución garantiza, procurando dar cumplimiento a los mandamientos del Bando de Policía y Gobierno y demás disposiciones reglamentariasqueexpida el ayuntamiento.

Figura 5. Instituciones de seguridad pública de los tres ámbitos.

\begin{tabular}{|l|}
\multicolumn{1}{c}{ Federal } \\
\hline - Sistema Nacional de \\
Seguridad Pública \\
(sNSP) \\
Policía Federal Preventiva \\
Policía de Federal de \\
Caminos \\
- Procuraduría General \\
dela República (PGR) \\
Agencia Federal de \\
Investigación (AFI) \\
- Instituto Nacional de \\
Migración (Inami) \\
Grupo BETA
\end{tabular}

Estatal

- Secretaría de Seguridad Pública Policía Estatal Preventiva

- Procuraduría General de Justicia del Estado (PGJE)

Policía Ministerial
Municipal

- Dirección de Seguridad

Pública Municipal

(Mexicali, Ensenada,

Tecatey Rosarito)

Policía Preventiva y

Policía de Tránsito

- Secretaría de Seguridad Pública Municipal Tijuana Policía Preventiva y

Policía de Tránsito

FUENTE: Elaboración propia. 


\section{Baja California y su legislación}

EN MATERIA DE SEGURIDAD PÚBLICA

Baja Cal ifornia ya había realizado lo propio desde 1989 en torno a la dinámica local dela seguridad pública; no obstantequelas modificaciones planteadas en 1994 le permitieron mejorar las relaciones con los tres ámbitos degobierno.

La legislación relacionada con la seguridad pública, en términos dela administración y procuración de justicia antes de 1994, era:

- Código Penal para el Estado de Baja California (1989).

- Código de Procedimientos Penales para el Estado de Baja California (1989).

- Ley de Seguridad Pública y Bases de Coordinación para el Estado de Baja Cal ifornia (1989).

- Ley Orgánica dela Procuraduría General de Justicia del Estado de Baja California (1989).

- Ley sobrela Procuraduría de los Derechos Humanosy Protección Ciudadana del Estado de Baja California (1991).

- Ley de Ejecuciones deSancionesy Medios de Seguridad para el Estado de Baja California.

- Ley Orgánica de la Defensoría de Oficio del Estado de Baja California (1981).

- Ley del Tribunal delo Contencioso Administrativo del Estado de Baja California (1989).

- Ley del Fondo A uxiliar para la Administración dejusticia del Estado de Baja Cal ifornia (1989).

- Ley del Indulto para los Reos del Fuero Común del Estado Librey Soberano de Baja California (1960).

- Ley para Menores Infractores en el Estado de Baja California (1993).

- Ley deDepósitos Constituidos en Materia deProcedimientos sobre Menores I nfractores del Estado deBaja Cal ifornia (1981).

En 1996, el gobierno del estado de Baja Cal ifornia incorporó en su agenda las facultades concurrentes con la federación en materia 
deseguridad pública, constituyendo el Consejo Estatal de Seguridad Pública como organismo permanente de coordinación con las autoridades federal es y municipales, e impulsando la conformación de instancias homól ogas en cada uno de los ayuntamientos del estado.

Durante 1997 la administración estatal presenta el Plan Estatal de Seguridad Pública y se crea la Secretaría Jurídica y de Prevención Social como dependencia encargada de las funciones dejusticia, readaptación social y seguridad pública. Esta dependencia asumió las funciones de prevención y readaptación social, defensoría de oficio y asesoría jurídica, así como brindar consejo jurídico al Gobierno del Estado y decoordinar el Sistema Estatal de Seguridad Pública.

En 1998 se modificó la Ley de Seguridad Pública y Bases de Coordinación del Estado para suplir lagunas jurídicas y actualizar el marco legal de las funciones y dependencias encargadas de la prevención del delito, la procuración de justicia y la readaptación social.

Sefirma el Convenio deCoordinación entrela Federación, Estado y los Municipios en Materia de Coordinación, por medio del cual las autoridades estatales y municipales tendrían acceso a los recursos financieros e instrumentos del Plan Nacional de Seguridad Pública a través del SNSP.

Asimismo, seinstaló el Consejo Regional de Seguridad Pública integrado por las autoridades de Sonora y Baja California, con la finalidad de unir esfuerzos para combatir la delincuencia mediante la coordinación, planeación y supervisión de las políticas en materia deseguridad pública.

Ese mismo año fue aprobada por el Congreso del Estado una nueva Ley Orgánica para la Procuraduría General de Justicia de Baja California, en la cual se establece la reestructuración de esta dependencia y, en especial , las funciones dela Policía Judicial del Estado, quesetransforma en Policía Ministerial. En 1999 se aprueba el nuevo Reglamento a la Ley queestablecela nueva estructura orgánica y funciones dela dependencia, así como las facultades y responsabilidades delas unidades administrativas quela integran. 
En ese mismo año es aprobado y publicado por el Congreso Local el Reglamento de Correctivos Disciplinarios para los Agentes dela Policía Ministerial y el Reglamento del Consejo deHonor y Justicia de la institución.

En el campo de la prevención, también en 1999 se conformó el ComitéEstatal dePrevención del Delito, con los objetivos decoordinar los esfuerzos de las diversas dependencias de los tres órdenes de gobierno en la entidad en aras de evitar la incidencia delictiva, particularmente en lo que se refiere al consumo de drogas, enervantes, psicotrópicos y estupefacientes.

En observancia a los objetivos del Sistema Nacional de Seguridad Pública y al Plan Estatal deDesarrollo 1996-2001, se constituyó el Consejo Ciudadano de Seguridad Pública con el propósito de integrar a las autoridades responsables de la seguridad pública y representantes dela sociedad. Con ello, seestablece un espacio de participación para la ciudadanía, en términos del diseño de las políticas en materia de seguridad pública en la entidad.

Durante el 2000, los esfuerzos se centraron en gran medida hacia la consolidación de convenios y acuerdos intergubernamentales, tanto con los estados queintegran la región noroeste del país, como con los estados vecinos de Cal ifornia y A rizona en Estados Unidos deAmérica.

En el 2001 es publicada la reforma de la Ley Orgánica de la Administración Pública Estatal, en donde se modifica la denominación dela Secretaría Jurídica y Prevención Social a la de Secretaría de Seguridad Pública.

En forma complementaria, se conforma la Policía Estatal Preventiva (PEP), en noviembre de 2001, la cual seconstituyecomo una instancia intermedia entrelas encargadas de los procesos de investigación para la procuración de justicia y las responsables de la prevención delos delitos.

A simismo, es publicada una nueva reforma a la Ley Orgánica de la Procuraduría General de Justicia del Estado, a efecto deincorporar en su art. 60. relativo a la definición de las instancias auxiliares del Ministerio Público, una fracción en donde se incorpora a los cuerpos deseguridad estatal y a las autoridades investigadores de 
Ios demás estados y la federación, en los términos delos convenios de cooperación quesecelebren.

\section{MARCO DE COLABORACIÓN INTERGUBERNAMENTAL}

Dentro del marco del federalismo, y de manera particular en las políticas de seguridad pública, vemos inmersas las relaciones intergubernamentales (RIGS), instrumentadas bajo una relación de interdependencia entre los tres órdenes degobierno y sustentadas bajo el principio de negociación, soportado con la regl amentación del art. 21 Constitucional, por medio dela Ley General queestablece las Bases de Coordinación del Sistema Nacional de Seguridad Pública.

Estas bases de coordinación contienen una visión integral al incluir no sólo las tareas de prevención de delitos y procuración de justicia, como la de administración de justicia y la aplicación de penas, sino queahora incorpora la prevención del delito como una atribución compartida por los tres órdenes degobierno, queantes sólo estaba delimitada a los municipios, cumpliendo con uno de los rasgos distintivos marcados por Wright, trascender las pautas de actuación gubernamental (citado en A granoff, 1997:127).

Es decir, estenuevo concepto de seguridad pública involucra la participación de los tres órdenes de gobierno en un esfuerzo conjunto y decoordinación, permitiendo establ ecer parámetros deintervención de cada uno de éstos mediante la conformación de acuerdos o convenios de coordinación entre las instituciones encargadas de la materia.

Ello no secontrapone con la distinción delas atribuciones jurisdiccionales de cada orden de gobierno, dado que el artículo 21 Constitucional establece que la función de la seguridad pública estará a cargo de los tres ámbitos degobierno respetando sus competencias; dicha función habrá de realizarse de manera coordinada. Prevaleceel principio de soberanía y autonomía de los estados hacia el interior desu demarcación territorial y jurisdiccional, como basefundamental del pacto federal; como el principio de una función compartida por éstos, que pese a reconocer el respeto a las 
competencias de cada uno, los ubica en una posición de iguales dentro deuna relación deinterdependencia.

En este sentido es como vemos la operatividad de las RIGs y en dondeadquieren una connotación queva másallá del significado del concepto de federalismo, el cual destaca primordialmente las relaciones estatales-nacionales; reconociendo las relaciones locales-nacionales, locales-estatal es e interregionales; es decir, el concepto de relaciones intergubernamentales abarca todas las combinaciones de relaciones entre las unidades de gobierno del sistema federal.

\section{CONCLUSIÓN}

Una de las graves situaciones que ha sufrido el país es la falta de coordinación entreinstituciones; el marco jurídico no permitió durante mucho tiempo la cooperación, las reglas impedían abarcar más allá de los límites estableci dos y cuando éstas se extendían en el ámbito territorial, los mismos lineamientos jurídicos bloqueaban la posi bilidad decumplir con la ley. Esto y una seriedeproblemas económicos, decrecimiento poblacional, demigración, dieron pauta al incremento delictivo, el cual rebasó las expectativasen la década de los noventa. Es hasta finales de 1994 que inician las modificaciones al art. 21 Constitucional, y al art. 115 principalmente, lo cual permitió sentar las bases jurídicas, operativas y estructurales de las instituciones a cargo de la seguridad pública para impulsar los mecanismos de coordinación, para determinar los lineamientos deacción entre las diversas instituciones deseguridad pública y reorganizar las relaciones intergubernamentales, permitiendo con ello quese pasara a operar bajo el modelo deautoridad superpuesta de Wright.

Se integraron acciones que sentaron las bases para la creación de sistemas de información sobre seguridad pública con captura, suministro, intercambio y sistematización dela información acerca de seguridad pública de cada una de las instancias involucradas. Esto ha permitido elaborar diagnósticos confiables con baseen los registros oficiales, elaborar programas preventivos y operativos, 
así como dar seguimiento y evaluar las acciones de los programas y las corporaciones relacionados con la seguridad.

Se empieza a trabajar en torno a las conferencias, en donde los secretarios de Seguridad Pública y los procuradores de Justicia instrumentan programas y acciones regionales y específicos, con objeto de atender la dinámica delictiva en forma conjunta. Asimismo, interactúan con el Consejo deSeguridad Públicay semantiene una di námica que se hace extensiva a todos los estados.

Esto es sólo el primer paso, el sustento deun marco jurídico y la reestructuración de la organización acorde a una realidad imperante, pero queda pendientefortalecer acciones tales como modificaciones en el sistema de otorgamiento derecursos, en dondelos estados y municipios tengan posibilidades de asignarlos con base en programas locales o regionales, a su capacidad administrativa y operativa, bajo sistemas de seguimi ento de programas, con mejor control sobrelos resultados, manteniendo la flexibilidad del sistema de Relaciones Intergubernamentales (RIGS), pero sobretodo de la gestión intergubernamental que desdeel municipio, sin menoscabo de la soberanía estatal y federal, pudieran implementarse y propiciar tanto la admi nistración como la operación de las instituciones encargadas dela seguridad pública.

\section{BiBLIOgRAFíA}

Agranoff, Robert. 1997. “Las relaciones y la gestión intergubernamental es”, en R. Bañón y E. Carrillo (comps.), La nueva administración pública, Alianza Universidad Textos, Madrid.

Aguilar Villanueva, Luis F. 1996. “Estudio introductorio”, Problemas Públicos y A genda deGobierno, Grupo Editorial Miguel Ángel Porrúa, México.

Carranza, Elías. 1997. “Situación del delito y dela seguridad delos habitantes en los países deA mérica Latina", en D el ito y seguridad delos habitantes, SigloXXI, Programa Sistema Penal Derechos Humanos de ILANUD y Comisión Europea, México. 
Centro deEstudios Económicos del Sector Privado. 2002. “La seguridad pública en México", Revista Entorno, núms. 166, 167 y 168, septiembrenoviembre, México.

Cooper, Doris. 2000. N ichos etiológi cos y características dela delincuencia urbana y rural mapuchey no-mapucheen Chile. Libros electrónicos, versión digital, www. rehue.csociales. uchile.cl/ personales/ dcooper/ c00.htm

Cornet, Prat Joan. 2002. “Inseguridad ciudadana: Ia psicología del miedo", Biblioteca de ideas, Revista Gobernanza y Seguridad Sostenible, España, 17 de diciembre. IISN 1695-1115. Versión digital. www.iigov.org/ seguridad/

Dammert, Lucía y A lejandra Lunecke. 2001. Victimización y temor en Chile. Revisión teórico-empírica en docecomunas del país, Centro de Estudiosen Seguridad Ciudadana, SerieEstudios, Chile.

Del Castillo, Arturo. 2001. El soborno: un marco conceptual para su análisis, vol. 10, CIDE.

Garrido, Vicente, Per Stangeland y Santiago Redondo. 1999. Principios de criminología, Tirant, "Criminología y Educación Social", Serie Mayor, España.

Gould, Peter. 1987. "Pensamientos sobre la geografía”, Cuadernos críticos de geografía humana, año XII, núm. 68, marzo.

Harvey, David. 1976. "Teoría revolucionaria y contrarrevolucionariaen geografía y el problema dela formación del ghetto", Cuadernos C ríticos de Geografía H umana, Universidad deBarceIona, año I, núm. 4, julio, España.

Houed, V. Mario. 1998. “Algunos aspectos importantes en el estudio y aplicación de la teoría del delito", Ciencias Penales, R evista dela A sociación de Ciencias Penal es de Costa Rica, año 10, núm. 15, diciembre, Costa Rica.

Instituto Interregional de las Naciones Unidas para Investigaciones sobre la Del incuencia y la Justicia (Unicri). 1995. Criminal $V$ ictimization of the D eveloping $W$ orld.

Mackinson, Gladis. La promesa dela sociología: mitosy reali-dades de la drogadicción. Disponible en Cuadernos de Bioética. Versión digital, sección Doctrina ISSN 0328-8390. www.cuadernos.bioetica.org/ 
Mascott Sánchez, María delos Ángeles. 2003. “Seguridad pública: incidencia delictiva y sensación de inseguridad". Versión digital. www.cddhcu.gob.mx/ cesop/ boletines/ no2/ 3.PDF. Julio.

Mejía Lira, José. 1999. “La importancia de las redes inter e intragubernamentales", G aceta M exicana, núm. 62, abril, INAP, México.

Mir, Nacis. 2002. “'Se desbordan los riesgos? Ley del desbordamiento del riesgo. Gobernalidad y seguridad sostenible". Agosto de 2002. Versión digital. www.iigov.org/ seguridad/ $? \mathrm{p}=6$ _04/ 7.

Prociuk, E. Gustavo. "Derecho Penal-Parte especial". Versión digital. www.derechoargentino.com.ar. A gosto de 2003.

Ramos García, José M aría. 1999. “Federal ismo, descentralización y relaciones intergubernamentales: una agenda para la toma dedecisiones político-administrativas", G aceta M exicana, núm. 62, abril, INAP, México.

Riella, Alberto. “Violencia y control social: el debilitamiento del orden social de la modernidad". Versión digital. http:/ / arje.hotusa.org/ socioart.htm.

Salinas Escobar, Mauricio y Loreto Hoecker. 2004. “La seguridad pública desde la perspectiva de la seguridad humana", Biblioteca de ideas, Revista Gobernanza y Seguridad Sostenible, núm. 15, febrero, España. IISN 1695-1115. [Versión digital] www.iigov.org/ seguridad/

Subirats, Joan. 1994. “Razones para un cambio de perspectiva en el estudio dela administración pública. El análisis delas políticas públicas", en Joan Subirats, A nálisis de políticas públicas y eficiencia de la administración, MAP, España.

Vértiz Galván, Miguel Ángel. 2001. “El combate a la corrupción en los trámites administrativos", G estión y Política Pública, Vol. 09, CIDE, México.

Wright, Deil. 1997. Para entender las relaciones intergubernamentales, FCE, M éxico. 